\title{
BLOG COMO FERRAMENTA PEDAGÓGICA NA PRODUÇÃO COLABORATIVA EM EDUCAÇÃO AMBIENTAL
}

\author{
Eliandra Gomes Marques ${ }^{1}$, Ilse Abegg ${ }^{2}$ \\ ${ }^{1}$ Educadora em economia solidária; com especialização em Educação Ambiental, em Mídias na Educação e em Gestão \\ Educacional pela Universidade Federal de Santa Maria (UFSM). \\ ${ }^{1}$ Doutora em Informática na Educação pela Universidade Federal do Rio Grande do Sul (UFRGS), professora da \\ UFSM/Centro de Educação/Departamento de Metodologia do Ensino; Pesquisadora UAB/CAPES e FAPERGS.
}

http://dx.doi.org/10.5902/223613085917

\section{RESUMO}

A história dessa pesquisa se deve às inquietações acerca do pouco emprego das mídias nas práticas pedagógicas e relata-se uma experiência que proporcione aos estudantes e professores outro olhar à produção do conhecimento. Nessa pesquisa, objetivou-se construir um ambiente para aprendizagem colaborativa apoiada por computador como estratégia de ensino-aprendizagem em educação ambiental. O bullying foi o recorte feito sobre a temática ambiental como forma de problematizar questões como a violência enquanto dispositivo de constituição dos sujeitos. Buscou-se desenvolver os princípios metodológicos da pesquisa-ação, que tem como características a ação, a pesquisa e a mudança de comportamento dos envolvidos, que, coletivamente, intervêm na ação em todas as suas fases, cuja finalidade comum é transformar a realidade. Os resultados demonstraram que os participantes utilizam de estratégias que cooperam para ações coletivas e participativas, demonstrando que o blog é uma ferramenta pedagógica que problematiza o processo de interação mediada por computador e à produção de textos colaborativos, assim contribuindo para que a educação seja transformadora, crítica e participativa.

Palavras-chave: produção colaborativa; mídias; educação ambiental; bullying; blog.

\section{ABSTRACT}

The history of this research is due to concerns about the little employment of pedagogical practices and media reported an experience that provides students and teachers another look to the production of knowledge. In this research aimed to build an environment for collaborative learning supported by computer as a strategy for teaching and learning in environmental education. The bullying was the trimming done on the environmental issue as a way to discuss issues such as violence as the constitution of the subject device. We sought to develop the methodological principles of action research, which has features like the action, research and change of behavior of those involved, who collectively are involved in the action in all its phases, whose common purpose is to transform reality. The results showed that the participants use strategies that work together for collective action and participatory, demonstrating that the blog is a pedagogical tool that discusses the process of interaction and computer-mediated collaborative text production, thus contributing to the education that is transformative, critical and participatory.

Keywords: collaborative production; media; environmental education; bullying; blog. 


\section{INTRODUÇÃO}

Este trabalho foi desenvolvido em uma escola pública estadual na região do extremo oeste de Santa Catarina (Brasil) e contou com a participação de estudantes, tanto o ensino fundamental (séries finais) quanto do ensino médio. Essa abertura às diferentes séries se deu pelo fato de possibilitar maior interação entre os estudantes em seus diferentes níveis de conhecimento.

Nessa pesquisa, discute-se que dentre as inúmeras possibilidades de práticas pedagógicas em educação ambiental estão aquelas que visam problematizar questões como a violência enquanto dispositivo de constituição dos sujeitos. Assim, é possível desenvolver os princípios da pesquisa-ação em educação ambiental fazendo um recorte da temática. O bullying foi o recorte feito sobre a temática ambiental como forma de problematizar questões como a violência enquanto dispositivo de constituição dos sujeitos.

A propósito, a abordagem da educação ambiental no contexto educacional consiste em propor outras formas metodológicas, abrindo espaço para o diálogo, e discutir novas formas de entender as relações do ser humano com seu meio, de tal modo que promova novas ações comportamentais que visem o desenvolvimento de uma sociedade sustentável, principalmente na prática de ações que contemplem a participação, formação e a autonomia do educando.

O bullying tem recebido grande destaque das mídias por ser uma questão que está fortemente relacionada às questões sociais. Por isso a escolha desse tema mobilizador se deu porque sua prevenção se constitui em uma necessária medida de educação que seja capaz de permitir o pleno desenvolvimento de crianças e adolescentes, habilitando-os à convivência social e ambiental. Tal medida é consequência de a agressividade estar presente principalmente no cotidiano das escolas, tornando-se não só um problema local, mas global. Por isso mesmo que a discussão sobre as problemáticas desencadeadas pelo bullying perpassa o contexto educacional e passa a ser um problema socioambiental. Assim, o objetivo geral dessa pesquisa é construir um ambiente para aprendizagem colaborativa apoiada por computador como estratégia de ensinoaprendizagem em educação ambiental.

Como objetivos específicos têm-se: (i) integrar as mídias na organização didáticometodológica; (ii) orientar o estudante para que o processo de ensino-aprendizagem aconteça de forma colaborativa e interativa, fazendo-o com que seja coautor; (iii) sensibilizar quanto à necessidade de ações para minimizar os impactos socioambientais; e (iv) promover a integração de mídias na temática da educação ambiental.

A escolha metodológica está focada na pesquisa-ação devido ao seu caráter de investigação estar centrado em questões e/ou situações de um determinado contexto e por apresentar as seguintes características une conhecimento científico e popular; se desenvolve em grupos de maneira participativa; facilita a interpretação que se efetua desde o ponto de vista dos participantes envolvidos na situação-problema; nasce desde e para a prática; contribui para relacionar teoria e prática; refleti sobre a prática vivida para melhorá-la, transformá-la e compreendê-la; permiti ao educador selecionar a direção a seguir frente às situações complexas e problemáticas. (MARQUES, 2011).

Este trabalho se justifica por apresentar uma prática interdisciplinar que valoriza a produção de leitura-escrita colaborativa para a construção de um blog, uma vez que a adoção de práticas que desvalorizam o conhecimento compartilhado e interdisciplinar ainda está presente no dia-a-dia da prática pedagógica. Nesse sentido, Morin (1991) destaca que "as disciplinas se fecharam sobre objetos mutilados. Assim, o conhecimento fechado destruiu ou ocultou em toda a 
parte as solidariedades, as articulações, a ecologia dos seres e dos atos, a existência!" (MORIN, 1991, p. 195). Sob esse mesmo enfoque, Fazenda (1991) destaca que é "difícil pensar em interdisciplinaridade quando fomos acostumados a pensar a educação compartimentalizada, produto da escola tecnicista." (FAZENDA, 1991, p. 56).

Portanto, o desafio que se coloca para os educadores é de efetivar uma prática pedagógica que seja crítica e interdisciplinar cujo enfoque busque uma perspectiva de ação sistêmica.

\section{MÍDIAS E INTERDISCIPLINARIDADE}

Apesar do avanço das mídias e sua utilização estar cada vez mais integrada ao dia-a-dia do ser humano, abrindo "novos espaços de construção do conhecimento." (COUTINHO e BOTTENTUIT JUNIOR, 2007, p. 199), ainda são pouco empregadas nas práticas pedagógicas. Gadotti (2000) afirma que:

Os sistemas educacionais ainda não conseguiram avaliar suficientemente o impacto da comunicação audiovisual e da informática, seja para informar, seja para bitolar ou controlar as mentes. Ainda trabalha-se muito com recursos tradicionais que não têm apelo para as crianças e jovens. (GADOTTI, 2000, p.5, grifo do autor).

O cenário atual delineia uma sociedade que pouco utiliza as mídias, sobretudo em contextos educacionais presenciais, pois ainda "se mantém nos métodos tradicionais de ensino, onde as tecnologias utilizadas não passam do quadro de giz, do retroprojetor e da escrita." (GUTIERREZ, 2005, p. 2).

Se por um lado, o que se tem mapeado é que as disciplinas estão cada vez mais "separadas e estanques em relação às demais disciplinas, tanto no conteúdo, quanto na metodologia." (ROSADO e BOHADANA, 2007, p. 2); por outro, o uso de mídias aponta sua importância na educação por possibilitar ações prático-educativas interdisciplinares. Assim, a experimentação de papéis retrata uma educação transformadora e emancipatória, em que o professor passa a ser mediador do ensino e da aprendizagem e os estudantes passam a experimentar uma nova prática de aprender-ensinar-aprender devido à abertura de experimentar o novo. Os estudantes passam a ser protagonista de uma sócio-construção de conhecimentos.

No entanto para haver práticas interdisciplinares é imprescindível que haja uma abertura do professor no sentido de propor novas formas pedagógicas que permitam o diálogo professorestudante e estudante-estudante para que se possa des-construir estruturas flexíveis, autônomas, críticas, justas, solidárias, sustentáveis, num contexto globalizado. Nesse sentido, a ação docente passa do ensinar para o "aprender a aprender" (MORAN, 2006).

Para essa efetivação, a troca de experiências e conhecimentos se faz necessária não só nos espaços educacionais formais para que, de fato, se trabalhe para uma formação interdisciplinar, mas também nos espaços não formais onde o conhecimento de mundo que os sujeitos trazem se articulam. Essa articulação de conhecimentos contribui na formação de uma visão sistêmica que, por sua vez, ajuda a compreender problemas e riscos desse contexto no qual os sujeitos estão inseridos.

Como expôs Freire (1997, p. 76), o sujeito tem que construir uma "capacidade de aprender, não apenas para nos adaptar, mas, sobretudo para transformar a realidade para nela intervir, recriando-a". Em sendo assim, é certo que se vive num contexto marcado por profundas mudanças 
econômica, social, cultural, ambiental, política, filosófica, que exigem dos sujeitos re-ver atitudes e escolhas.

Destarte, romper com estruturas fragmentadas e com os limites do conhecimento é estabelecer elos, possibilitar infinitas inter-relações, dialogar com outros sujeitos, com isso permitindo um desvelar da visão de si mesmo enquanto sujeitos e a visão de mundo, reconhecendo a complexidade dos diferentes contextos e compreendendo-os como parte do processo de superação de fronteiras disciplinares e conceituais.

Sendo assim, nesse trabalho, busca-se uma interação com ênfase na relação dialógica que se estabelecerá entre os aprendentes no momento de suas atividades de aprendizagem colaborativa. Por isso, a escolha em desenvolver uma prática a partir do recorte temático bullying por ser uma atitude comportamental que se manifesta tanto dentro quanto fora da escola.

Em virtude disso que essa proposta vem trazer uma forma metodológica de inserir a discussão do bullying como mobilizador de ações transformadoras através da educação ambiental.

A educação ambiental considera o meio ambiente em sua totalidade, estimula o exercício pleno e consciente da cidadania e fomenta o resgate e o surgimento de novos valores que tornem a sociedade mais justa, solidária e sustentável. E essa educação promove o diálogo entre os indivíduos, fazendo-os que tenham uma visão da parte como um todo, e vice-versa, que os fatos não sejam vistos isoladamente, mas em sua totalidade e complexidade.

É uma educação que integra os conhecimentos, fazendo-os inter-relacionarem-se, e que vem para modificar o quadro de insustentabilidade global causada pela fragmentação, limitação e desarticulação do processo de conhecimento, do predomínio da visão cartesiana, da falta de estabelecer relações sociais.

Pode-se afirmar, portanto, que educação ambiental é um processo contínuo no qual os indivíduos e a sociedade constroem suas consciências sobre seu ambiente e adquirem o conhecimento, os valores, as habilidades, as experiências e a determinação que os tornem aptos a agir, tanto individual como coletivamente.

Para obter um efeito positivo desse processo de produção do conhecimento, a atividade de aprendizagem colaborativa vai ser o fio condutor para a efetividade de práticas simples mas que vêm "fomentar processos inovadores de leitura e de escrita que envolvam e os transformem, simultaneamente, em leitores e autores" (TAMAR, 2009, p. 99).

Ao trazer uma prática que valoriza a aprendizagem colaborativa de um tema ambiental, toca-se no mais precioso bem que os sujeitos detêm: a educação. Ela é o "elemento indispensável para a transformação da consciência ambiental." (BRASIL, 1997, p. 24).

Por ser o espaço dessa pesquisa conhecido dos sujeitos envolvidos, isso favorece a compreensão dos problemas comuns e a busca pela solução ou minimização deles, todavia desde que sejam trabalhados coletivamente. Para isso, foi trazida uma metodologia interdisciplinar que utiliza a ferramenta blog para desenvolver uma produção colaborativa de leitura e escrita.

\section{Blog}

O blog é um ambiente virtual em que são publicados em pequenos blocos textos dispostos em ordem cronológica reversa cujos conteúdos postados recentemente se encontram na parte superior da página.

No Brasil, os blogs passaram a ser objetos de estudos "por trazerem a possibilidade de novos modos de pensar o uso da tecnologia na educação" (GUTIERREZ, 2005, p. 3) e por serem 
fáceis a sua criação, edição e publicação. A razão dessa facilidade se deve às diversas ferramentas disponibilizadas em um mesmo espaço que "é construído e colocado on-line por meio de um aplicativo que realiza a codificação da página, sua hospedagem e publicação." (GUTIERREZ, 2005, p. 3).

Igualmente, vale enfatizar que o acesso ao conteúdo do blog é público e gratuito, podendo nesse espaço se dar uma relação de cooperação entre os autores e leitores por meio de comentários que podem ser filtrados pelos administradores.

Por meio de sua funcionalidade, o blog educativo possibilita a interação entre os sujeitos devido ao seu caráter dinâmico e sua simples manutenção e facilidade de acesso aos registros e até pode ser usado como um recurso pedagógico complementar de atividades e avaliações extraclasse.

Os blogs apresentam características que favorecem um processo de comunicação interativa e compartilhada entre os estudantes e desses com os professores sobre temas estudados em sala de aula. São práticas motivadoras que propiciam a vivência de situações de aprendizagem colaborativa no contexto educacional.

Barbosa e Serrano (2005) trazem o blog como uma ferramenta de apoio à prática pedagógica. Para as autoras o blog é um ambiente facilitador para a produção coletiva de conteúdos escolares que potencializa a construção coletiva, viabilizando a interação, colaboração e a cooperação entre os envolvidos.

Sob o ponto de vista da colaboração, o blog garante a sócio-construção do conhecimento que ocorre pela ação coletiva e fundamenta a elaboração de soluções de problemas. A proposição da aprendizagem colaborativa como estratégia para a sócio-construção do conhecimento facilita a participação ativa dos estudantes na atividade.

\section{Aprendizagem Colaborativa}

A aprendizagem colaborativa é um modelo de prática pedagógica que supera a reprodução do conhecimento e prioriza a construção social desse conhecimento, a partir de uma visão sistêmica. É uma estratégia de ensino que valoriza o trabalho coletivo, proporciona a interação entre os envolvidos por meio de uma abordagem progressista. Nesse contexto, os estudantes passam a ser construtores e socializadores de conhecimentos por meio do diálogo com o outro. Corroborando com essa prática, Abegg e outros (2009) destacam que:

as plataformas colaborativas acrescentam outras perspectivas ao processo de ensinoaprendizagem, proporcionando novas maneiras de realizar as atividades de estudo, agregando dimensões como planejamento colaborativo de projetos com aplicações e funcionalidades específicas, nos quais professores e alunos podem trabalhar em rede, colaborativamente, sobre um tema (ABEGG et al, 2009, p.1644).

Por isso que a aprendizagem colaborativa demanda uma conduta cooperativa, ou seja, que os sujeitos envolvidos no processo de aprendizagem realizem as tomadas de decisões, o planejamento e as ações coletivamente, e que as discussões sejam críticas e reflexivas. Mais ainda as mídias estão se tornando instrumentos indispensáveis do processo educativo.

Diferentemente, das práticas tradicionais que privilegiam contextos de aprendizagem individual, a aprendizagem colaborativa 
é uma estratégia de ensino que encoraja a participação do estudante no processo de aprendizagem e que faz da aprendizagem um processo ativo e efetivo, onde o conhecimento é resultante de um consenso entre membros de uma comunidade, algo que as pessoas constroem conversando, trabalhando juntas e chegando a um acordo. (ROMANÓ, 2004, p. 320).

Nesse sentido, o estudante, à medida que interage com seus colegas o-Outro e começa a ter fluência sobre os objetos de aprendizagem, torna-se um participante ativo nesse processo e passa a ter condições de construir seu conhecimento.

Corroborando com essa prática no processo educativo, Bittencourt e outros (2004, p. 2) destacam que "o objetivo maior da pedagogia colaborativa é que os ambientes por ela utilizados sejam ricos em possibilidades e propiciem o crescimento de um grupo", posto que a aprendizagem não se dá de forma isolada e solitária, mas no diálogo entre os sujeitos.

Os desafios da prática pedagógica estão centrados em processos de aprendizagem que deem autonomia aos estudantes já que ainda é utopia a aprendizagem baseada em práticas que demandem uma educação que provoque ações colaborativas em um paradigma emergente, instrumentalizado pelas mídias (MORAN, 2006).

Sob esse aspecto, Leite (2008) coloca que, em análise à integração de mídia no contexto educacional,

identificamos aí um dos grandes obstáculos no sistema educacional, uma vez que, mesmo inserindo alguma mídia na prática pedagógica, a escola funciona, de maneira geral, fundamentada no paradigma da simplicidade, no qual tudo é mecânico, reducionista, linear, tendo a pretensão de formar cidadãos para um mundo no qual o paradigma que se apresenta é o da complexidade, ou seja, aberto, interdisciplinar, colaborativo, hipertextual. (LEITE, 2008, p.72).

Contudo, é pertinente destacar a urgência de a educação deixar a "obsolescência da sala de aula centrada na pedagogia da transmissão" (FREIRE, 2008, p. 80) e passar a incorporar pedagogias que levem em conta a colaboração como processo criativo e colaborativo de educação.

Para discorrer sobre a metodologia desse trabalho investigativo, optou-se por utilizar as fases da pesquisa-ação, segundo Thiollent (1997), que são: fase exploratória, fase principal, fase de ação e fase de avaliação. (MARQUES, 2010; 2011).

\section{O espaço-tempo das mídias no contexto da pesquisa}

Esta é a fase exploratória da pesquisa em que são diagnosticados os problemas e buscados coletivamente caminhos para minimizá-los ou solucioná-los. É também feito o reconhecimento do espaço a ser investigado ou onde estão inseridos os objetos de estudo. Elegeu-se, como elementos do diagnóstico, a escola, a sala de informática, as mídias disponíveis e as mídias usadas pelos professores para ensino-aprendizagem.

A escola onde foi realizada a pesquisa possui uma sala climatizada e equipada com 15 computadores conectados à internet e com software livre, um projetor multimídia com tela para projeção e um aparelho de som com microfone e caixas de som para apresentações com áudio. A sala é utilizada para pesquisa pelos estudantes e professores, no entanto apenas uma professora 
da área de linguagens - língua espanhola, a usa como espaço de ensino-aprendizagem em sua prática pedagógica.

A partir desse diagnóstico, propôs-se à escola desenvolver um trabalho de pesquisa com estudantes e professores que proporcionasse a construção coletiva do conhecimento por meio das interações sociais a partir da construção e edição de um blog.

Os professores acharam interessante a proposta, mas somente disponibilizaram suas aulas, caso fosse necessário, para o andamento do trabalho, entretanto não quiseram se envolver justificando que estavam sobrecarregados de atividades. Tal recusa pode ser pelo fato de muitos não terem fluência tecnológica sobre as mídias, em especial a informática, ou por não haver interesse em estar abrindo novas possibilidades de inclusão de ferramentas tecnológicas em sua prática pedagógica já que essa inserção deve estar no planejamento das aulas.

Ao serem indagados sobre a não utilização de mídias em suas práticas pedagógicas, alguns professores responderam que não têm tempo para um trabalho mais elaborado e que faltam cursos de formação sobre mídias. Sobre essa afirmação foi constatado que poucos professores participaram do curso "Mídias na Educação", que foi oferecido aos professores da rede pública de ensino. Somente participaram alguns da rede municipal de ensino e participaram somente do curso de extensão.

Também os estudantes, quando perguntados se sabiam utilizar as mídias como ferramenta de aprendizado, a maioria respondeu que apenas usava a informática para pesquisas e para envio de mensagens pelo correio eletrônico e páginas de relações sociais. A aceitação da escola se deu por ser um projeto inovador que valoriza as mídias no ensino-aprendizagem.

O primeiro encontro com os estudantes se deu na sala de informática da escola. Foi feita a apresentação do projeto de concepção de um blog que trouxesse informações acerca da concepção de educação ambiental, bem como se realizou o planejamento das ações coletivamente definindo, dentre outros pontos, quando seria o próximo encontro e quem seriam os facilitadores.

\section{Construção coletiva do blog "Educação Ambiental”}

Esta fase compreende a etapa principal que é marcada pela construção do blog "Educação Ambiental". Nesta fase foram definidas a identidade visual do blog a partir da percepção do grupo sobre o entendimento do que é educação ambiental e a interação entre os sujeitos a cerca das ferramentas do aplicativo Blogger da Google, para que o grupo, através do compartilhamento de sabres e conhecimentos, do diálogo, adquira fluência tecnológica.

Destaca-se que a escolha desse aplicativo da Google se deve ao fato de ser uma versão livre e disponibilizada em rede, pela facilidade de acesso aos conteúdos dos internautas sendo desnecessários código de acesso e senha, apenas são identificados pelo endereço eletrônico ou sítio, à exceção dos autores.

A construção do blog contou com a ajuda daqueles estudantes que já tinham fluência tecnológica dessa ferramenta e compartilharam conhecimentos com os demais integrantes da pesquisa. Embora os participantes conhecessem as ferramentas de correios eletrônicos e sítios de relacionamentos, apenas um já havia construído uma ferramenta desse tipo.

Durante as interações foram apontadas pistas que permitiram desconstruir e construir o blog tanto em aspectos técnicos e comunicacionais (layout, plano de fundo, inserção de componentes e links) como nas produções escritas postadas. 
A busca pela identidade visual do blog se deu pela relação que os estudantes tinham com a compreensão do que era educação ambiental. Mesmo após terem se familiarizado com esse conceito, optou-se em não alterar o plano de fundo por remeter à simbologia da esperança em sensibilizar e conscientizar os cidadãos sobre o respeito com seus semelhantes e consigo mesmo, conforme a figura 2 .

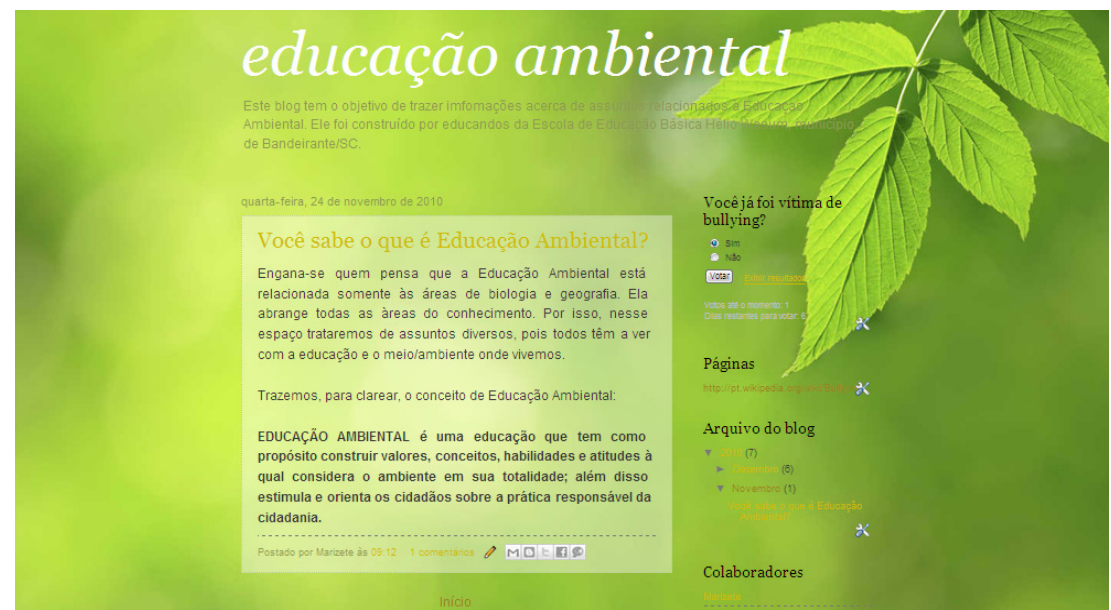

Figura 2 - Identidade visual do blog e conceituação de educação ambiental.

O plano de fundo remete, segundo o grupo, à natureza, ao cuidado com os elementos (água, solo, ar, resíduos). Dessa relação estabelecida de que a educação ambiental está relacionada exclusivamente às áreas de Biologia e Geografia, por meio de um diálogo presencial, a professorapesquisadora fez um breve relato sobre a concepção de educação ambiental e seus usos, e, a posteriori, sugeriu ao grupo uma pesquisa na internet e em mídia impressa (livros, revistas e periódicos disponíveis na biblioteca municipal) sobre o conceito até para delimitar o foco.

Segundo Reigota (2001a), a educação ambiental

\footnotetext{
deve ser entendida como educação política, no sentido de que ela reivindica e prepara os cidadãos para exigir justiça social, cidadania nacional e planetária, autogestão e ética nas relações sociais e com a natureza. (REIGOTA, 2001a, p.10).
}

Nesse sentido, o estudante deve ser autor de sua própria história de mudança e estão nas mãos do educador as ferramentas para auxiliar nessa transformação socioambiental. Nas palavras de Moran (2006, p. 71), para tal efetivação, "o inovador precisa ser criativo, articulador e, principalmente, parceiro dos estudantes no processo de aprendizagem". Em virtude disso, o educador para ser "inovador" deve preocupar-se em criar problematizações que levem o estudante a acessar os conhecimentos e aplicá-los, fazendo-o refletir sobre a realidade, bem como administrar conflitos na escola e fora dela. Portanto, é nesse espaço-tempo que as mídias precisam estar contempladas na prática pedagógica.

\section{Produção colaborativa}

Definida como a "fase da ação", as primeiras produções colaborativas foram concebidas no terceiro encontro, o qual foi marcado pelo compartilhamento de saberes adquiridos a partir das 
pesquisas realizadas. Os estudantes trouxeram conceitos de educação ambiental para que pudessem refletir coletivamente e construir um conceito que desse conta de definir educação ambiental com suas compreensões, que pode ser visualizado na figura 2; e em seguida, definiu-se o tema mobilizador que nortearia as postagens e comentários no blog, como pode ser observado na figura 3.

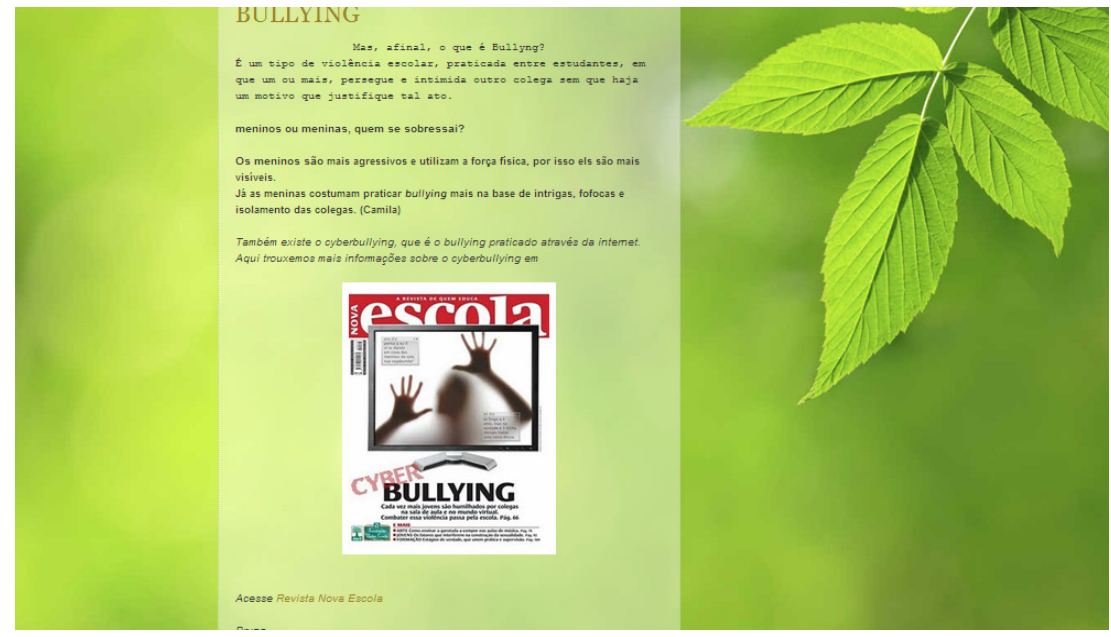

Figura 3 - Tema mobilizador e inserção de hipertextos

Os textos publicados são importantes para clarificar que a produção do saber demanda ações que levem os educadores e os educandos a buscarem processos de investigação-açãoreflexão. Ainda na figura 3, é possível verificar que, a partir da definição do leiaute do blog, os envolvidos na pesquisa começaram a postar textos e inserir hipertextos.

Cabe aqui ressaltar a importância de o estudante problematizar sua realidade, pois é um momento motivador para a sua aprendizagem e para também avançar com ela. Estudos como os de Pereira (2002) mostram que o professor deve ser ousado em transgredir as práticas tecnicistas e viabilizar espaços de conhecimento abertos, flexíveis e colaborativos.

O aluno deve ser estimulado a ir além do conteúdo abordado em sala de aula, participando ativamente do processo ensino-aprendizagem pesquisando, questionando, relatando suas experiências. Tal prática visa o desenvolvimento das capacidades de socialização e de aprendizagem colaborativa, indispensáveis nos dias de hoje. (PEREIRA, 2002, p.1).

Ainda outras fontes foram disponibilizadas no blog para que o leitor possa navegar em sítios sobre bullying, proporcionando, com isso, um aumento nas informações sobre a temática ambiental de modo que transporte o leitor para outro espaço virtual, dando o formato ao blog arquivos de textos com várias ligações, por exemplo, o sítio da enciclopédia virtual denominada de Wikipédia que traz o conceito de bullying.

A Wikipédia é um espaço livre disponibilizado na internet que traz informações sobre diversos assuntos e também é um espaço que facilita a produção colaborativa através da ferramenta wiki. Corroborando com essa ferramenta, Abegg e outros (2009) destacam que "após o surgimento da Wikipédia, o processo de produção colaborativa tornou-se mais universal." (ABEGG et al, 2009, p. 1). Entretanto, os autores reiteram uma preocupação dos pesquisadores em educação de que, "infelizmente, a produção colaborativa no âmbito escolar ainda é pouco 
concretizada, talvez pelo fato da escolaridade estar centrada na individualidade e competitividade e não na colaboração entre os pares." (ABEGG et al, 2009, p. 2).

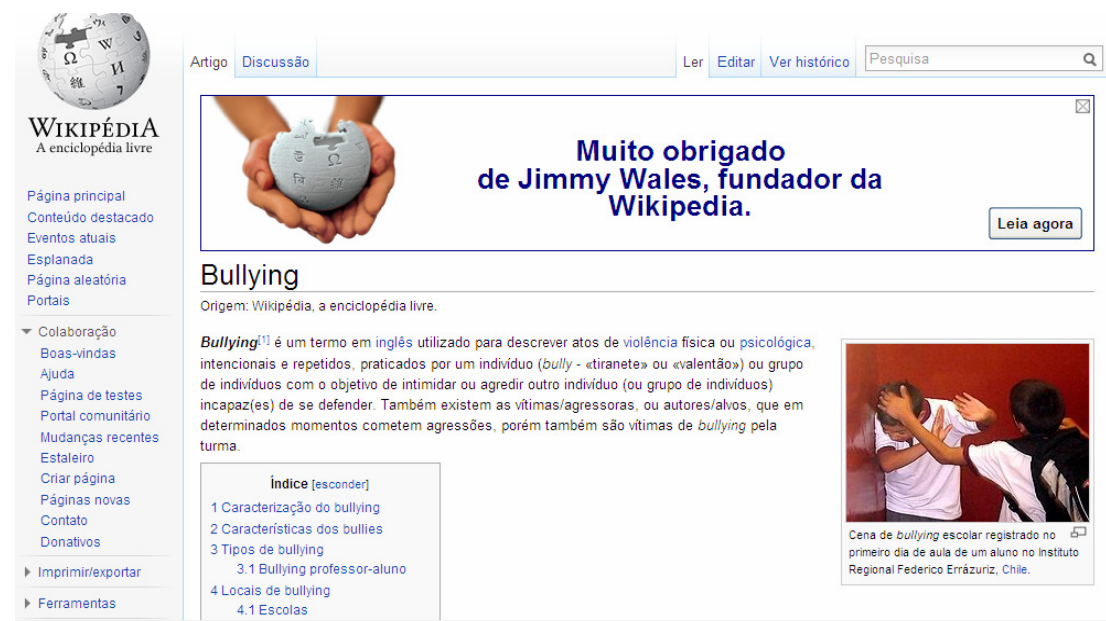

Figura 4 - Página da Wikipédia que contém informações sobre bullying.

A página, como pode ser visualizada na figura 4, traz elementos importantes acerca do bullying da escrita hipertextual. Para isso, a inserção de outras mídias fez com que o grupo pudesse utilizar-se de outros espaços midiáticos em rede, proporcionando, assim, a conexão com ambientes virtuais que auxiliam na compreensão macro da temática abordada.

A integração de mídias é um recurso usado para enriquecer o ambiente. Após pesquisa de vídeos disponíveis no You Tube, a inserção de um vídeo sobre o tema mobilizador foi disponibilizado no blog. Devido à sua linguagem não-verbal, nesse exemplo, o vídeo faz o leitor refletir sobre as cenas, imaginá-las e transportá-las para a sua realidade, como pode ser vista na Figura 6.

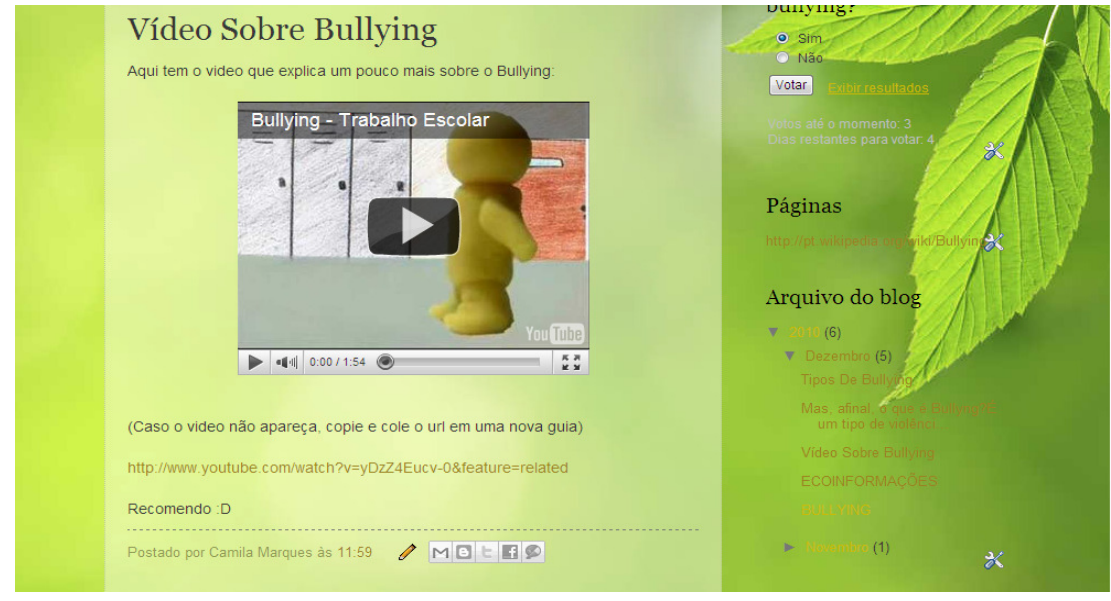

Figura 6 - Inserção da mídia vídeo.

Com uma linguagem simples e sem falas, o vídeo traz em seu enredo uma sequência de ações de bullying praticada por estudantes no ambiente escolar. O vídeo foi descoberto dentre os inúmeros que apareceram sobre o tema em questão, e foi aquele que despertou interesse pelo diferencial: de ter sido construído por estudantes. O grupo definiu-o como um exemplo que podia 
ser compartilhado no blog com destaque para os elementos empregados em sua criação como situações parecidas àquelas vividas ou vivenciadas pelos estudantes nos diversos espaços da escola e até fora dela.

Importante destacar que a mídia informática vem para corroborar para a criação de espaços que utilizam a produção colaborativa como mediadora do processo de ensino-aprendizagem, como aponta Lévy (2006, p. 64):

A ajuda ao trabalho em equipe representa uma aplicação particularmente promissora dos hipertextos: ajuda ao raciocínio, à argumentação, à discussão, à criação, à organização, ao planejamento, etc. O usuário destes programas para equipes é explicitamente um coletivo.

Diante do exposto, o diferencial dessa mídia está na aplicação da linguagem do hipertexto e também pela integração de outras mídias para a construção de objetos de aprendizagem.

\section{Avaliação e Feedback}

Constatou-se que estava sendo a primeira experiência dos estudantes em atividade colaborativa e mediada por mídias, o que demonstrou melhor motivação em participar da pesquisa.

A realização desse trabalho proporcionou uma percepção da realidade que quer mudança. Isso foi facilitado porque, quando os conhecimentos são articulados, a capacidade de enfrentar os problemas também se modifica. Isso ocorreu porque o diálogo entre todos os sujeitos participantes da pesquisa (estudantes e professora-pesquisadora) e o trabalho participativo estabeleceram uma relação entre os conhecimentos, um compartilhamento de saberes.

A produção colaborativa foi uma forma de os estudantes buscarem informações e também compartilharem com outros colegas, pais, professores e comunidade escolar e virtual. Essa prática possibilitou-os a interação e a colaboração entre o grupo.

Também o recorte da temática ambiental fez com que cada um do grupo refletisse sobre a importância de sua atuação na prevenção desse fenômeno socioambiental, e pudesse levar ao conhecimento de professores e profissionais da educação para que possam diagnosticar e tratar dos possíveis danos ao ambiente escolar e ao desenvolvimento de crianças e adolescentes, além da necessidade deles orientar as famílias e a sociedade para o enfrentamento da forma mais frequente de violência juvenil que é o bullying.

As etapas de identidade visual, criação e administração do blog foram realizadas pelo grupo, mediante a discussão e a participação. O processo de pesquisa e de produção colaborativa na temática escolhida, que contemplou um assunto que vem sendo discutido atualmente por ser um dos problemas que assolam as relações socioambientais, fez com que os estudantes demonstrassem interesse e motivação e começassem a diagnosticar questões que afetam não só o meio em que vivem, mas o todo.

\section{CONCLUSÕES}

Observou-se que o uso do blog como ferramenta para a produção colaborativa, a qual se deu de forma coletiva, participativa e autônoma, facilitou a ação-reflexão sobre os problemas socioambientais relacionados ao bullying e favorecendo a autoria coletiva. Por meio do diálogo, foi 
possível estabelecer a ordem de prioridades dos problemas pesquisados e das soluções a serem encaminhadas sob a forma de ação concreta.

Evidenciou-se que o blog, como ferramenta para a aprendizagem colaborativa, traz benefícios ao processo de ensino-aprendizagem de estudantes nas mais diversas áreas do conhecimento. Por isso, é viável os professores integrarem o blog de forma complementar às suas práticas pedagógicas até para trabalhar com interdisciplinaridade de temas.

Contudo, enquanto os professores não deixarem sua imagologia de seres supremos do saber e adotarem posturas transformadoras nas práticas pedagógicas como a inserção das mídias na condução do conhecimento, proporcionando aos estudantes que sejam também coautores de seus conhecimentos, a educação continuará opressora. Dar espaço a práticas que estimulem a produção do saber e não sua simples reprodução como na abordagem tecnicista.

Conclui-se que a criação e a produção colaborativas trouxeram uma satisfação aos sujeitos envolvidos na pesquisa a cada ação, a cada limite vencido coletivamente, sobretudo ao produto final que se constituiu como um ambiente de dados que, estando em rede, pode ser acessado e utilizado por quem tiver interesse na temática versada. Outrossim, a colaboração favoreceu compreender que a educação ambiental está nas ações diárias que se realizam não importando qual contexto se está.

Fecha-se a pesquisa, concordando com Reigota (2001b, p. 112): "sem uma transformação das consciências e dos comportamentos das pessoas" não haverá mudança no todo ambiente e essa mudança de postura se faz pela educação ambiental aliada a práticas pedagógicas que têm em sua centralidade a aprendizagem colaborativa.

\section{REFERÊNCIAS BIBLIOGRÁFICAS}

ABEGG, I. et al. Aprendizagem Colaborativa em rede mediada pelo wiki do Moodle. jul. 2009. Disponível em: <http://portalsbc.sbc.org.br/?module=Public\&action=SearchResult\&author=232>. Acesso em: $8 \mathrm{dez}$. 2009.

BARBOSA, C. A. P.; SERRANO, C. A. O blog como ferramenta para construção do conhecimento e aprendizagem colaborativa. 2005. Disponível em: <www.abed.org.br/congresso2005/por/pdf/011tcc3.pdf>. Acesso em: 18 jan. 2011.

BITTENCOURT, C.S. et al. Aprendizagem colaborativa apoiada por computador. Revista Novas Tecnologias na Educação, $\quad$ v. 2, n. 1 , mar. $2004 . \quad$ Disponível em: <http://www.cinted.ufrgs.br/renote/dez2007/index.html>. Acesso em: 8 dez. 2009.

BRASIL. Ministério da Educação. Parâmetros Curriculares Nacionais: Meio Ambiente e Saúde, v. 9. Brasília: MEC, 1997.

COUTINHO, C. P.; BOTTENTUIT JUNIOR, J. B. Blog e Wiki: Os Futuros Professores e as Ferramentas da Web 2. In: IX Simpósio Internacional de Informática Educativo SIIE 2007, nov. 2007, p. 199-204. Disponível em: <https://repositorium.sdum.uminho.pt/bitstream/1822/7358/1/Com\%20SIIE.pdf>. Acesso em: 17 jan. 2011.

FREIRE, P. Pedagogia da Autonomia - Saberes necessários à prática educativa. São Paulo: Paz e Terra (Coleção Leitura), 1997.

FREIRE, W. (Org.). Tecnologia e Educação. As mídias na prática docente. Rio de Janeiro: Wak, 2008.

GADOTTI, M. Perspectivas atuais da Educação. São Paulo em Perspectiva, v. 14 n. 2, São Paulo abr/jun 2000. Disponível em: <http://www.scielo.br/scielo.php?pid=S0102$88392000000200002 \&$ script=sci_arttext>. Acesso em: 20 set. 2010. 
GUTIERREZ, S. Weblogs e educação: contribuição para a construção de uma teoria. In: Revista Novas Tecnologias na Educação, v. 3, n. 1, mai. 2005. Disponível em: <http://www.cinted.ufrgs.br/>. Acesso em: 12 jul. 2010.

LEITE, L. S. Mídia e a perspectiva da tecnologia educacional no processo pedagógico contemporâneo. In: FREIRE, W. (Org.). Tecnologia e Educação. As mídias na prática docente. Rio de Janeiro: Wak, 2008.

LÉVY, P. As Tecnologias da Inteligência. O futuro do pensamento na era da informática. Tradução Carlos Irineu da Costa. Rio de Janeiro: Editora 34, 2006.

MARQUES, E. G. Educação Ambiental e Tecnologia Social: juntas por um desenvolvimento rural sustentável. 2010. 67f. Monografia (Especialização em Educação Ambiental) - Universidade Federal de Santa Maria, Santa Maria, 2010.

A Construção do Projeto Político-Pedagógico da Economia Solidária. 2011. 47f. Monografia (Especialização em Gestão Educacional) - Universidade Federal de Santa Maria, Santa Maria, 2011.

MORAN, J. M.; MASETTO, M. T.; BEHRENS, M. A. Novas Tecnologias e Mediação Pedagógica. São Paulo: Papirus, 2006.

MORIN, E. O Método, v.1. A natureza da natureza. Portugal: Publicações Europa-América, 1991.

OLIVEIRA, E. da S. G. de; REGO, M. C. L. C.; VILLARDI, R. M. Aprendizagem mediada por ferramentas de interação: análise do discurso de professores em um curso de formação continuada a distância. In: Educação \& Sociedade, Campinas, v. 28, n. 101, p. 1413-1434, set./dez. 2007. Disponível em: <http://www.cedes.unicamp.br>. Acesso em: 30 out. 2009.

PEREIRA, A. L. V. O uso de ambientes virtuais colaborativos como apoio ao ensino presencial. In: 6 Congresso Iberoamericano, 4 Simpósio Internacional de Informática Educativa, 7 Taller Internacional de Software Educativo, 2002. Disponível em: <http://www-gist.det.uvigo.es/ie2002/actas/paper-125.pdf>. Acesso em: 10 dez. 2009.

REIGOTA, M. O que é educação ambiental. São Paulo: Brasiliense, 2001a. Meio Ambiente e Representação Social. São Paulo: Cortez, 2001b.

ROMANÓ, R. S. Ambientes virtuais para a aprendizagem colaborativa no ensino fundamental. REVISTA NOVAS TECNOLOGIAS NA EDUCAÇÃO, v. 2. n. 1, mar., 2004. Disponível em: <http://www.cinted.ufrgs.br/renote/mar2004/index.html>. Acesso em: 10 dez. 2009.

ROSADO, L. A. da S.; BOHADANA, E. Autoria coletiva na educação: análise da ferramenta wiki para cooperação e colaboração no ambiente de aprendizagem Moodle. In: VI Encontro de Educação e Tecnologias da Informação e Comunicação (E-TIC), nov. 2007. Disponível em: <http://etic2008.files.wordpress.com/2008/11/unesaluizalexandre.pdf>. Acesso em: 15 jun. 2010.

TAMAR, L. Blogs pedagógicos: possibilidades de interação por meio da escrita coletiva de hipertextos cooperativos. Revista Latinoamericana de Tecnologia Educativa - RELATEC, 8 (2), 91-108. Disponível em: <http://campusvirtual.unex.es/cala/editio>. Acesso em: 23 dez. 2009.

THIOLLENT, M. Pesquisa-Ação em Organizações. São Paulo: Atlas, 1997.

TOZZONI-REIS, M. F. C. Pesquisa-Ação: compartilhando saberes; Pesquisa e Ação educativa ambiental. In: Encontros e Caminhos: formação de educadoras (es) ambientais e coletivos e coletivos educadores. Brasília: MMA, 2005. 